\title{
The interplay of IL-21 and BAFF in the formation and maintenance of human B cell memory
}

\section{Jodi L. Karnell and Rachel Ettinger *}

Medlmmune LLC, Gaithersburg, MD, USA

\section{Edited by:}

Katja Fink, Agency for Science,

Technology and Research A*Star,

Singapore

Reviewed by:

Kishore Alugupalli, Thomas Jefferson University, USA

Anne Davidson, Feinstein Institute for Medical Research, USA

*Correspondence:

Rachel Ettinger, Medlmmune, One

Medlmmune Way, Gaithersburg, MD 20878, USA.

e-mail: ettingerc@medimmune.com
To date, IL-21 stands out as the most influential cytokine for human B cell activation and differentiation. Indeed, when compared to other important B cell tropic cytokines such as IL-2, IL-4, IL-6 and IL-10, IL-21 is clearly the most potent in terms of its ability to influence humoral immune responses in humans. IL-21 has wide reaching actions in determining how $B$ cells will respond to co-stimulation ranging from induction of cell death upon BCR crosslinking to potent induction of class switch recombination and plasma cell differentiation when CD40 molecules are co-engaged. Another crucial B cell factor, exemplified in recent clinical trials, is BAFF/BLys. BAFF plays a critical role in the survival of human B cells and plasma blasts and influences $B$ cell expansion and migration. Recent evidence has shown that IL-21 and BAFF can work in concert to promote and perhaps maintain humoral immunity in humans. Notably, BAFF has the unique ability to substitute for CD4OL activities in regard to IL-21-co-stimulation and differentiation of a specific B cell subpopulation located in the human splenic marginal zone. However, and perhaps surprisingly, BAFF signals do not have the capability to override IL-21-driven cell death events when BCR is engaged. In stark contrast, anti-CD40 ligation of B cells co-activated with IL-21 and anti-lgM not only reverses this aforementioned activation-induced cell death, but transforms this death signal into one that drives plasma cell differentiation. Here we will discuss these two critical B cell factors, IL-21 and BAFF, and their distinct and complimentary effects on human B cell responses.

Keywords: IL-21, BAFF, BLys, human B cell

\section{INTRODUCTION}

Memory B cells are generated following antigen exposure and represent a population of cells capable of mounting a swift and robust secondary response to antigen re-encounter. In the case of immunization, memory B cells are critical for maintaining a protective humoral response to pathogens and may persist for decades (Lanzavecchia and Sallusto, 2009). However, re-activation of memory B cells with self-reactive potential can lead to the production of autoantibodies and promote autoimmune disease. Understanding the pathways that promote the activation, differentiation, and maintenance of naïve and memory B cells is crucial for discerning the mechanisms that underlie autoimmune disorders. This review will highlight the unique and synergistic effects of IL- 21 and BAFF on various subsets of human B cells.

\section{IL-21: A COMMON $\gamma$ CHAIN CYTOKINE WITH PLEIOTROPIC ACTIVITIES}

IL-21 is a member of the common gamma chain $\left(\gamma_{c}\right)$ receptor cytokine family with significant homology to IL-2, IL-4, and IL15 (Ozaki et al., 2000; Parrish-Novak et al., 2000). IL-21 was first identified as a factor produced by in vitro-activated human CD3+ $\mathrm{T}$ cells and was later shown to be produced by NK T cells and CD4+ T cells (Parrish-Novak et al., 2000; Chtanova et al., 2004; Rasheed et al., 2006; Coquet et al., 2007). While various human CD4+ helper T cell subsets express IL-21 mRNA, including Th1 and Th17 cells, Tfh cells are the most abundant producers of IL-21
(Chtanova et al., 2004; Rasheed et al., 2006). We found that IL-21 is spontaneously produced by tonsillar $\mathrm{T}$ cells in the absence of stimulation (Kuchen et al., 2007). Similar findings were reported by Bryant et al. (2007) who identified the IL-21 producing cells as CD4+ CXCR5+ Tfh cells.

IL-21 signals through a receptor complex consisting of its own private receptor, the IL-21R, and the $\gamma_{c}$ (Asao et al., 2001; Spolski and Leonard, 2010). Engagement of the IL-21R/ $\gamma_{c}$ complex leads to the activation of several signaling pathways including the Jak/STAT, MAPK, and PI3K pathways (Habib et al., 2002; Davis et al., 2007; others). IL-21R is expressed on a broad array of cell types including B cells, T cells, NK cells, macrophages, and dendritic cells, as well as other hematopoietic and non-hematopoietic cells such as fibroblasts, keratinocytes, and intestinal epithelial cells (Spolski and Leonard, 2008b). On B cell subsets, IL-21R is expressed on resting naïve and germinal center (GC) B cells and is upregulated following anti-CD40 activation of both naïve and memory B cells (Good et al., 2006). IL-21 up-regulates expression of its own receptor either alone or in combination with anti-CD40 (Ettinger et al., 2008b).

IL-21 has been reported to modulate various aspects of immune function. IL-21 promotes CD4 T cell differentiation and expansion, CD8 T cell and NK cell expansion, and cytolytic activity, as well as inhibits dendritic cell maturation and antigen presentation and also has a variety of other effects on both hematopoietic and non-hematopoietic cells (Spolski and Leonard, 2008a). Perhaps 
one of the most striking activities of IL-21 is its ability to sculpt the humoral immune response. Although much has been done in various mouse systems to reveal the effect of IL-21 in murine B cell biology, the following will focus exclusively on the role of IL-21 in human B cell immuno-regulation.

\section{CONTEXT DEPENDENT INFLUENCE OF IL-21 ON HUMAN B CELL EXPANSION AND PLASMA CELL DIFFERENTIATION}

The process by which a naïve or memory $B$ cell is activated and differentiated into an Ig secreting plasma cell involves a series of steps, several of which have been shown to be regulated by IL-21. Initially following activation, $\mathrm{B}$ cells are induced to divide and expand. IL21 promotes robust B cell expansion following CD40 engagement on both naïve and memory B cells isolated from either cord blood or peripheral blood whereas CD40 engagement alone results in minimal proliferation (Parrish-Novak et al., 2000; Ettinger et al., 2005). It has been demonstrated that human splenic and tonsillar $\mathrm{B}$ cell subsets also proliferate extensively under these conditions (Good et al., 2006; Ettinger et al., 2007, 2008b).

Following B cell expansion, the proper signals can induce B cells to undergo class switch recombination (CSR), affinity mature, and differentiate into plasma cells. IL-21 plays a complex role in these $\mathrm{B}$ cell fate decisions. In combination with CD40 ligation, IL-21 induces CSR, plasma cell differentiation, and Ig production from B cells isolated from various lymphoid compartments via the induction of activation-induced deaminase (AID), a required factor for somatic hypermutation and CSR, and BLIMP-1, a transcriptional repressor involved in plasma cell differentiation (Pene et al., 2004; Ettinger et al., 2005; Bryant et al., 2007). IL-21 co-stimulation, however, does not initiate somatic hypermutation in vitro despite the induction of AID (Ettinger et al., 2005).

IL-21 has the unique ability to induce cord blood naïve B cells to maximally differentiate into plasma cells by co-stimulation with CD40 engagement (Ettinger et al., 2005; Bryant et al., 2007). No other cytokine to date has this same potential, including the combination of IL-2/IL-10 and anti-CD40 or IL-10 and CD40L which has been shown to induce plasma cell differentiation of memory splenic B cells (Ettinger et al., 2005; Bryant et al., 2007). Furthermore, as cord blood B cells are exquisitely sensitive to death by BCR crosslinking, co-engagement of BCR with IL-21 and CD40 ligation not only inhibits cell death, but augments expansion, CSR, plasma cell differentiation, and Ig production. Specifically, cord blood B cells switch to IgG3 following IL-21 co-stimulation whereas peripheral blood or splenic naïve B cells switch to IgG1 and IgG3 (Pene et al., 2004; Ettinger et al., 2005). Additionally, IL-21 polyclonally activates CD27+ memory B cells resulting in production of all Ig isotypes (Ettinger et al., 2005). IL-21 is also capable of stimulating IgA production from naïve cord blood or total CD19+ peripheral blood derived B cells (Ettinger et al., 2005; Avery et al., 2008a). IL-21 co-activation was not reported to induce IgA from total splenic B cells (Pene et al., 2004). Notably, however, IL-21 co-stimulation with anti-CD40 does not have the capacity to drive isotype switching to IgE (Pene et al., 2004; Ettinger et al., 2005). Finally, in addition to synergizing with T cell-derived signals such as CD40, IL-21 can also combine with CpG-induced TLR-9 signals to promote Ig secretion by peripheral blood B cells (Massonnet et al., 2009).
High affinity antibodies are often generated by GC-resident B cells. IL-21 also potently drives plasma cell differentiation and antibody production from human splenic GC B cells, inducing production of IgM, IgG, and IgA antibodies (Bryant et al., 2007). While IL-10 was previously believed to be the critical B cell differentiation factor, IL-21 co-stimulation with CD40 engagement results in the generation of $\sim 20$-fold more Ig secreting cells than does the combination of CD40 ligation and IL-10 from splenic GC or blood B cells (Ettinger et al., 2005; Bryant et al., 2007).

Within the splenic microenvironment of the GC, B cells interact with a several cell types but the hallmark of humoral immune responses is mediated by $\mathrm{B}$ cell/T cell interactions, in which both cell bound receptor/ligand interactions as well as $\mathrm{T}$ cell-derived cytokines play a vital role (Jelinek and Lipsky, 1985). The above studies have demonstrated that purified recombinant IL-21 costimulated with anti-CD40 or CD40L-expressing cells can mimic $\mathrm{T}$ cell dependent $\mathrm{B}$ cell responses. However, the milieu of cytokines and co-receptor engagement that follows $\mathrm{T}$ cell activation is difficult to recapitulate using recombinant proteins. The critical role of IL-21 in direct T cell-driven B cell responses was demonstrated in ex vivo co-culture systems in which $\mathrm{T}$ cells are polyclonally activated (Bryant et al., 2007; Kuchen et al., 2007). We found that blockade of endogenously produced IL-21 following CD4+ $\mathrm{T}$ cell activation was sufficient to significantly inhibit B cell expansion, plasma cell differentiation, and antibody production (Kuchen et al., 2007). Blockade of other cytokines, specifically, IL-2, IL-4, or IL-10 did not have the ability to reduce IgG production, however, anti-IL-4 in combination with anti-CD40L did lessen plasma cell differentiation. Inhibition of other individual cytokines was found to diminish IgM production albeit to a lesser extent than did blockade of IL-21 (Kuchen et al., 2007). Importantly, in co-culture assays using naïve or memory B cells stimulated with activated $\mathrm{T}$ cells, IL-21R-Fc inhibited IgM production from naïve B cells and IgG production from both naïve and memory B cells, while it had much less impact on IgM production from pre-switched memory B cells (Kuchen et al., 2007). Although IL-21 is able to co-stimulate plasma cell differentiation of pre-switched splenic memory B cells, post-switched B cells are more sensitive to IL-21 activity (Bryant et al., 2007; Kuchen et al., 2007). The above findings support a mechanism whereby IL-21 co-stimulation is critical for plasma cell differentiation of naïve $\mathrm{B}$ cells and also plays an important role in plasma cell differentiation of post-switched memory B cells. IgM production from pre-switched memory B cells, however, is controlled by many cytokines, including IL-21, as well as additional factors such as TLR ligands (Bernasconi et al., 2002).

IL-21 can be stimulatory or inhibitory depending on the context in which the IL-21 signal is delivered. Several studies have demonstrated that the effect of IL-21 is modulated by other cytokines. Importantly, the two $\gamma_{c}$ cytokines, IL-4 and IL-21, have both synergistic and opposing activity. One of the first studies to demonstrate this showed that IL-21 inhibits B cell expansion induced by IL- 4 and BCR ligation (Parrish-Novak et al., 2000). IL21 does, however, have the ability to greatly enhance IL-4 induced IgE production when CD40 molecules are co-engaged (Pene et al., 2004; Wood et al., 2004; Avery et al., 2008b). Other reports suggest that IFN $\gamma$ production by $\mathrm{T}$ cells and NK cells as well as polymorphisms in the IL-21R inhibit IL-21's capacity to promote 
IgE in the context of IL-4 stimulation (Pene et al., 2006). The potential of these two $\gamma_{c}$ cytokines, however, to synergize, is limited to IgE. We have reported that IL-4 greatly inhibits IL-21-driven plasma cell differentiation and IgG production, especially when BCR is co-engaged with CD40 ligation or superantigen (Ettinger et al., 2005). Down regulation of AID and BLIMP-1 appears to be the mechanism by which IL-4 limits IL-21activity (Ettinger et al., 2005). Avery et al. (2008a) reported that while IL-4 inhibits IL21 and CD40L-induced switching to IgA and IgG3, it increases switching to IgG1. Cumulatively, these data suggest a complex, dynamic relationship between IL-21 and IL-4 in driving B cell responsiveness.

In addition to expansion and differentiation, IL-21 also influences B cell survival. In contrast to its ability to synergize with anti-CD40 to induce B cell proliferation and differentiation, IL21 triggers cell death when BCR is ligated (Ettinger et al., 2005, $2008 \mathrm{~b})$. This induction of cell death is preceded by activation and several rounds of proliferation, suggesting that IL-21 is inducing an activation-induced type of cell death which can be reversed by addition of either anti-CD40 or IL-4 (Ettinger et al., 2005, 2008b). IL-21 also directly triggers cell death of B cell chronic lymphocytic leukemia (CLL) cells, the most common type of adult leukemia, irrespective of whether CD40, BCR, or BAFF receptor (BAFFR) are co-engaged (de Totero et al., 2006; Jahrsdorfer et al., 2006; Ettinger et al., 2008b).

This autoregulatory function of IL-21 on B cell survival in both malignant CLL and non-malignant primary B cells was recently explained by the observation that IL-21 has the ability to induce granzyme B $(\mathrm{GzmB})$ resulting in the differentiation of cytolytic B cells (Jahrsdorfer et al., 2006; Hagn et al., 2009). Treatment of CLL cells with IL-21 and CpG leads to apoptosis of both the GzmB producing cells themselves as well as bystander cells (Jahrsdorfer et al., 2006). Induction of GzmB is more robust in naïve compared to memory B cells and is greatly augmented by BCR ligation (Hagn et al., 2010, 2011). Importantly, CD40 signals inhibit IL-21 induced GzmB production thereby shifting B cell differentiation away from cytotoxicity and toward a plasma cell fate (Hagn et al., 2011). These data reflect the potential of IL-21 to influence B cell mediated immune responses in multiple ways. Early in the response to an infection when pathogens may engage the BCR in the absence of direct T cell help, IL-21, produced by bystander T cells, directs B cells to produce GzmB and kill infected cells. However, later in the response as direct $\mathrm{T}$ cell help becomes available, IL-21 synergizes with CD40L to promote the differentiation of plasma cells which can secrete antibodies directed against extracellular pathogens.

Cumulatively, these data suggest a model in which IL-21 plays a critical role in B cell fate decisions. IL-21 serves as a stimulator of $\mathrm{B}$ cell responses when delivered in the context of direct $\mathrm{T}$ cell help. Alternatively, IL-21 in combination with BCR ligation induces cell death in the absence of cognate T cell help. This function of IL-21 is a potential mechanism whereby autoreactive B cells are kept in check when the BCR is crosslinked by auto-antigen. However, in the presence of autoreactive $T$ cells capable of delivering contactdependent help in the context of CD40L, IL-21's death signal is converted to one which promotes plasma cell differentiation and ultimately production of pathogenic autoantibodies. These data along with the observations that IL-21 levels are elevated in the serum of lupus patients and polymorphisms in the IL-21R confer risk for systemic lupus erythematosus (SLE) suggest that targeting the IL-21 pathway may have therapeutic benefits in settings of autoimmunity (Ettinger et al., 2008a,b; Webb et al., 2009; Wong et al., 2010). Two clinical trials are/were ongoing utilizing IL-21/IL-21R blockade in normal and autoimmune individual (NovoNordisk, 2010; Pfizer, 2010).

\section{IMPAIRED B CELL MEMORY IN HUMANS WITH DEFECTIVE IL-21 SIGNALING PATHWAYS}

Binding of IL-21 to its receptor activates several members of the Jak-STAT pathway, including Jak1, Jak3, STAT1, STAT3, and STAT5. In resting human B cells, activation of STAT3 is most prominent in response to IL-21 (Habib et al., 2002; Diehl et al., 2008). Importantly, STAT3 appears critical for IL-21's role in driving plasma cell differentiation, as expression of a constitutively active STAT3 in human B cells was sufficient to induce BLIMP-1 upregulation and antibody production (Diehl et al., 2008).

Additional support for the critical role of STAT3 downstream of IL-21 comes from studies of patients with STAT3 mutations. Ex vivo studies with $\mathrm{B}$ cells from these individuals reveal that the synergistic effect of IL-21 and IL-4 on IgE production was lost in patients with STAT3 mutations (Avery et al., 2008b). More in depth analysis of these patients revealed reduced frequencies of circulating memory B cells compared to healthy donors or patients with STAT1 mutations (Avery et al., 2010). Levels of circulating anti-tetanus IgG were found to be reduced in STAT3 mutant patients and in vitro recall experiments demonstrated that both the overall frequency and affinity of antigen specific $\mathrm{B}$ cells was also lower in these individuals. Finally, mutations in STAT3 largely impaired IL-21-mediated B cell expansion and plasma cell differentiation (Avery et al., 2010). Interestingly, however, while the overall number of antibody producing cells was reduced following stimulation with IL-21 and CD40L, the relative proportion of STAT3 mutant B cells that expressed IgG1 was comparable to healthy controls, demonstrating that while plasma cell differentiation is diminished these cells are still capable of CSR. While STAT3 mutant B cells fail to upregulate BLIMP-1 in response to IL-21 and CD40L, upregulation of AID was unaffected by this mutation. These data suggest that IL-21-mediated induction of AID and class switching is STAT3-independent, while STAT3 is critical for IL-21-induced B cell expansion, differentiation, and/or survival. Together, the above data define a role for IL-21 in the generation and maintenance of $\mathrm{B}$ cell memory.

\section{BAFF: TNF FAMILY CYTOKINE WITH COMPLEX BINDING PARTNERS}

Another critical factor in promoting B cell responses is BAFF/BLys ( $B$ cell activating factor). BAFF is a member of the TNF family of cytokines and exists as either a membrane bound or soluble form. Initial descriptions suggested that BAFF expression was limited to lymphoid tissue and was produced by cells of the myeloid lineage (Moore et al., 1999; Schneider et al., 1999). In particular, BAFF secretion was detected in dendritic cells and in cultures of monocytes stimulated with IFN $\gamma$ (Moore et al., 
1999). Additional stimuli, such as LPS and IFN $\alpha$, elicited production of both membrane and soluble BAFF by monocytes, while IFN $\alpha$ potently stimulates BAFF production by dendritic cells (Litinskiy et al., 2002). More recent studies show however, that a number of additional cell types, including activated $\mathrm{T}$ and $\mathrm{B}$ cells, epithelial cells, neutrophils, and astrocytes, are also capable of producing BAFF (Scapini et al., 2003; Krumbholz et al., 2005).

BAFF binds to three different cell surface receptors, BAFFR, B cell maturation protein A (BCMA), and transmembrane activator and CAML interactor (TACI), listed in order of affinity for BAFF (Gross et al., 2000; Thompson et al., 2000, 2001). Much work has been done to define the expression pattern of these receptors on various B cell subsets. BAFFR is the most widely expressed of the BAFFRs. Specifically, BAFFR is found on all peripheral blood B cells, as well as naïve, memory, and marginal zone (MZ) splenic $\mathrm{B}$ cells and both naïve and memory tonsillar B cells ( $\mathrm{Ng}$ et al., 2004; Zhang et al., 2005; Darce et al., 2007b; Ettinger et al., 2007). Tonsil GC B cells also express BAFFR, albeit at lower densities than the other tonsillar B cell subpopulations ( $\mathrm{Ng}$ et al., 2004). Bone marrow resident CD138+ plasma cells, however, lack expression of BAFFR (Darce et al., 2007b).

The receptors TACI and BCMA, on the other hand, are upregulated with differentiation. Whereas naïve $B$ cells do not express TACI and BCMA, TACI upregulation closely follows that of the memory B cell marker CD27 (Darce et al., 2007b), and remains expressed on plasma cells. TACI is also expressed on splenic memory and MZ B cells and to a much lesser extent on follicular B cells (Ettinger et al., 2007). BCMA is found upregulated on tonsillar GC B cells and is expressed on plasma blasts/plasma cells at high densities (Ng et al., 2004; Zhang et al., 2005). However naïve and memory B cells as well as splenic MZ B cells do not appear to express BCMA (Darce et al., 2007b; Ettinger et al., 2007).

An additional level of complexity in the regulation of BAFFR expression involves changes in receptor expression with activation. Naïve B cells upregulate TACI following activation with various stimuli including $\mathrm{CpG}$ alone or BCR ligation in combination with CD40 ligation and cytokine signals such as IL21 and IL-10 (Darce et al., 2007b). We have shown that activation/differentiation of peripheral blood $B$ cells with a combination of IL-21, anti-CD40, and anti-IgM results in significant upregulation of BCMA on the IgD-CD38++ plasma cells which develop in these cultures (Ettinger et al., 2005). Modulation of the three BAFFRs following activation has also been reported in that CD40L/IL-2/IL-10 stimulated B cells were shown to downregulate BAFFR while upregulating TACI on specific $\mathrm{B}$ cell subpopulations (Avery et al., 2003). Moreover, in this system, upregulation of BCMA was also noted, but it followed after many rounds of cell division (Avery et al., 2003). Likewise, B cells activated with the combination of CpG/IL-2/IL-15 downregulate BAFFR with concurrent upregulation of BCMA on the memory B cell compartment (Darce et al., 2007b). These studies demonstrate the complex nature of BAFF signaling in $\mathrm{B}$ cells and suggest that this pathway is involved in regulating the response of both resting and activated $B$ cells at several stages of differentiation.

\section{BAFF REGULATES HUMAN B CELL SURVIVAL, GROWTH, AND ANTIBODY PRODUCTION}

Early studies demonstrated that BAFF, in either membrane bound or soluble form, can combine with BCR ligation to stimulate the growth of $\mathrm{B}$ cells derived from peripheral blood or tonsil (Moore et al., 1999; Schneider et al., 1999). BAFF likely plays a critical role in regulating $\mathrm{B}$ cell expansion in vivo as blockade of BAFF inhibits both macrophage- and dendritic cell-driven B cell expansion in vitro (Craxton et al., 2003).

BAFF also controls B cell homeostasis by regulating $\mathrm{B}$ cell survival. BAFF alone promotes the survival of human splenic $B$ cells, and in particular memory B cells are most sensitive to the anti-apoptotic effects of BAFF (Avery et al., 2003). In vitro, BAFF has only a modest effect on the survival of naïve B cells and does not regulate the survival of circulating human transitional B cells (Avery et al., 2003; Sims et al., 2005). The prosurvival effect of BAFF on memory B cells is independent of an effect on proliferation as BAFF alone does not induce memory $B$ cells to undergo cell division. The effect of BAFF in mouse models is quite distinct from human ex vivo studies, as several reports have demonstrated that murine memory B cells are BAFF-independent (Benson et al., 2008; Scholz et al., 2008). In contrast to mouse studies, the mechanism whereby BAFF regulates human $\mathrm{B}$ cell survival does not involve modulation of the pro-apoptotic factor Bim (Craxton et al., 2003; Ettinger et al., 2007).

In addition to promoting the survival of resting human memory cells, BAFF also increases the survival CD38+ plasmablasts. BAFF and CD40L appear to target distinct memory B subpopulations in this regard as CD40L stimulation preferentially increases the survival, but not proliferation of CD38- B cell blasts (Avery et al., 2003). Despite its pro-survival effects, however, BAFF is unable to protect naïve $B$ cells against cell death induced by the combination of IL-21 and BCR signaling (Ettinger et al., 2007, 2008b).

An in vivo correlation between BAFF levels and B cell numbers was demonstrated in studies of patients receiving B cell depletion therapy. Following B cell depletion in patients with rheumatoid arthritis (RA), for example, serum BAFF levels rise significantly and remain elevated for varying periods of time (Cambridge et al., 2006). Importantly, decreased BAFF levels were then associated with the reemergence of B cells in the periphery. Mechanistically, increased BAFF protein levels likely arise from a decreased pool of the BAFFRs following B cell depletion. Additionally, however, BAFF mRNA levels are also increased following B cell depletion, suggesting transcriptional control of BAFF is modulated by loss of B cells (Lavie et al., 2007). Moreover, patients with elevated baseline BAFF levels have shorter clinical responses to B cell depletion therapy. More specifically, there was a positive associate between patients with quantifiable pre-B cell depletion therapy BAFF levels and early flares following B cell depletion. These observations may suggest that elevated BAFF levels influence B cell repopulation following depletion (Cambridge et al., 2008).

In addition to regulating survival, BAFF also works in concert with B cell tropic cytokines to induce AID and CSR and to promote plasma cell differentiation. We have noted minimal effect on AID, BLIMP-1, CSR, and plasma cell differentiation when BAFF 
is added alone to cultures of purified human naïve or memory $\mathrm{B}$ cells (Ettinger et al., 2007). However, BAFF synergizes with IL-10 or TGF $\beta$ to induce CSR of IgD+ peripheral blood B cells from $\mathrm{C} \mu$ to $\mathrm{C} \gamma$ or $\mathrm{C} \alpha$ or with IL-4 to induce switching to $\mathrm{C} \varepsilon$ (Litinskiy et al., 2002). BAFF used with IL-4 up-regulates IgG and IgA on the cell surface, however, BCR crosslinking is required for secretion of antibodies (Litinskiy et al., 2002). Importantly, co-culture of BCR-activated peripheral blood B cells with IFN $\alpha$-activated dendritic cells induced plasma cell differentiation and the production of IgA and IgG antibodies, which was largely inhibited by BAFF blockade (Litinskiy et al., 2002). More recent studies suggest that BAFF can synergize with IL-17 to promote the survival of naïve and memory B cells and in combination with anti-CD40 and anti-IgM, BAFF and IL-17 can substitute for TLR signals to drive $B$ cell expansion and plasma cell differentiation (Doreau et al., 2009). IL-17 and BAFF in combination with CD40 and BCR signaling induces production of all Ig isotypes in vitro, however, IgM is the dominant isotype detected in these cultures. Both BAFF and IL-17 levels are elevated in SLE patients, suggesting these two cytokines may promote the survival and activation of autoreactive B cells in vivo in settings of autoimmunity (Doreau et al., 2009).

BAFF also has the capacity to impact Ig production from CD38+, but not CD38-, activated memory B cells. BAFF stimulation in combination with IL-2 and IL-10 globally augmented the generation of Ig producing cells from the activated memory $\mathrm{B}$ cell pool, with the most pronounced effect on cells producing IgA (Avery et al., 2003).

BAFF, however, does not always serve as a positive regulator of $B$ cell activation. In contrast to its ability to stimulate proliferation and Ig production in combination with BCR ligation and cytokines, BAFF inhibits differentiation and Ig secretion from CpG-stimulated cells (Darce et al., 2007a). Importantly, when compared to IL-21 stimulation, BAFF alone or in combination with anti-CD40 with or without anti-IgM, had minimal ability to induce plasma cell differentiation or IgG production from total splenic B cells (Ettinger et al., 2007).

Finally, BAFF also has the ability to influence the migratory response of B cells, as BAFF selectively synergizes with CXCL13 to enhance the chemotactic response of human tonsillar memory $\mathrm{B}$ cells (Badr et al., 2008). The synergy of BAFF and CXCL13 on B cell chemotaxis implies that BAFF may influence the formation of $B$ cell areas and GCs in both lymphoid and non-lymphoid areas.

\section{BAFF BLOCKADE AS A TREATMENT FOR AUTOIMMUNE DISEASE}

The ability of BAFF in combination with B cell tropic factors to stimulate the growth of B cells and to promote memory B cell survival, CSR, and antibody production suggest that BAFF would be an excellent target for neutralization in settings of autoimmunity where pathogenic autoantibody production contributes to disease progression. Circulating BAFF levels are elevated in a number of autoimmune diseases including SLE, RA, and Sjogren's syndrome. Moreover, in lupus patients BAFF levels correlate with disease activity (Cheema et al., 2001; Groom et al., 2002; BeckerMerok et al., 2006). To date BAFF inhibitors have been tested in clinical trials for patients with SLE, RA, and multiple sclerosis.
Atacicept/TACI-Ig, which inhibits both BAFF and its homolog APRIL (a proliferation inducing ligand), partially reduces B cell numbers in patients with mild to moderate SLE (Dall'Era et al., 2007). Patients receiving repeat dosing of the drug developed an initial transient increase of total B cells followed by a sustained reduction of $45-60 \%$ of total B cell numbers relative to baseline. This reduction of $\mathrm{B}$ cells correlated with decreased circulating IgM, IgG, and IgA levels, suggesting that differentiation and/or survival of plasma cells was being affected. The most dramatic effect was observed on IgM titers which were reduced nearly $50 \%$ compared to baseline in patients receiving repeated doses (Dall'Era et al., 2007). Similarly, in a trial with RA patients, repeat dosing of atacicept reduced IgG, IgA, and IgM levels by 21,37 , and 54\%, respectively (Tak et al., 2008). Importantly, a decrease in rheumatoid factor antibody titers was also noted in treated patients compared to placebo controls.

Within the last year, a BAFF-neutralizing monoclonal antibody, belimumab (Benlysta ${ }^{\circledR}$ ), received FDA approval as the first new therapeutic to treat SLE in over 50 years. In a Phase II clinical trial with SLE patients, belimumab, like atacicept, reduced overall circulating B cell numbers (Wallace et al., 2009). Additionally, circulating antibodies of all Ig isotypes were reduced by belimumab, including IgE which declined by as much as 34\%. Notably, autoantibodies such as anti-dsDNA were also reduced. Treatment with belimumab led to undetectable anti-dsDNA IgG titers in 15\% of patients compared to $3 \%$ of patients in the placebo group. In this study, however, there were no significant changes in disease activity at the study endpoint (Wallace et al., 2009). A follow-up Phase III study was conducted of longer duration and employed different endpoint criteria. This study showed that belimumab in combination with standard of care resulted in a modest but significant clinical improvement compared to placebo (Navarra et al., 2011).

Surprisingly, in contrast to what is observed in vitro where memory B cells appear to be highly sensitive to BAFF, clinical trials have demonstrated that it is naïve and transitional B cells which are particularly susceptible to BAFF inhibition in vivo (Jacobi et al., 2010). Numbers of transitional and naïve B cells were significantly decreased at day 84 following belimumab treatment, and continued to decline up to day 532, reaching decreases of 88 and 75\%, respectively (Jacobi et al., 2010). On the other hand, at an early time point (day 84) numbers of memory B cells were actually increased. This increase in memory B cell number was transient, yet much longer periods of time ( $>1$ year) were required to note depletion of memory $B$ cells and plasma cells following treatment with Belimumab (Jacobi et al., 2010). The differential effects of BAFF in vitro and in vivo suggest that while BAFF plays a critical role in regulating many aspects of B cell function, additional factors, such as IL-21 may influence memory B cell survival and differentiation in vivo.

Clinical trials also demonstrated that BAFF blockade preferentially targets IgM secreting cells, while IgG production is largely unaffected (Jacobi et al., 2010). The ability of Belimumab to target IgM may be due to decreases in naïve B cells which are thought to give rise to short-lived IgM producing plasmablasts, while GC $\mathrm{B}$ cells, which largely give rise to IgG producing cells, may be 
less susceptible. This possibility is supported by observations in mice which demonstrate that GC formation occurs in a BAFFindependent manner (Rahman et al., 2003). Additionally, mouse studies also suggest that APRIL is more prominent than BAFF in regulating plasma cell survival (Belnoue et al., 2008), which may contribute to the inability of Belimumab to inhibit IgG levels. Together, these data suggest that combination therapeutics which block BAFF along with other B cell tropic factors may be required to more effectively target memory B cells and long lived plasma cells.

\section{BAFF AND IL-21 SYNERGIZE TO STIMULATE HUMAN B CELL MEMORY}

Maintenance of serologic memory requires the survival and differentiation of memory B cells, both of which are influenced by IL-21 and BAFF. Memory B cells are located in several compartments, including blood and lymphoid tissue such as lymph nodes and spleen. Unlike mice, the human spleen contains specialized IgD+ and IgD- memory B cells located in the MZ that are somatically mutated (Dunn-Walters et al., 1995; Tangye et al., 1998; Weller et al., 2005). Previously, we have characterized these $\mathrm{B}$ cells both phenotypically and functionally and termed them MZ-analog (MZA) B cells as they localize around the follicular $\mathrm{B}$ cell zone in an area similar to that of the mouse MZ (Ettinger et al., 2007). MZA B cells have a unique phenotype including high expression levels of CD21, CD27, B220, and CD45RA while lacking expression of CD23, compared with peripheral blood and splenic non-MZA memory B cell populations that do not express high densities of CD21, and express lower levels of CD27. MZA B cells also highly express both BAFFR and TACI (but not BCMA) and like follicular B cells, survival of MZA B cells is increased by BAFF (Ettinger et al., 2007).

Not only are MZA B cells distinct in their phenotype, they also are hyperresponsive to signals that mimic $\mathrm{T}$ cell activation. In vitro activation of sorted human splenic $B$ cell populations revealed that IgG+ MZA B cells are exquisitely sensitive to IL-21 and anti-CD40 stimulation compared to follicular B cells. Both the extent and rate of plasma cell differentiation and production of IgG antibodies was greatly increased over the other splenic naïve and memory B cell subpopulations (Ettinger et al., 2007).

IgG+ MZA B cells are also unique in respect to signals capable of driving their differentiation into plasma cells. In most cases, when TLR ligands are not engaged, plasma cell differentiation requires a combination of $\mathrm{B}$ cell tropic cytokines, CD40 stimulation, and/or BCR ligation. However, we found that IgG+ MZA $B$ cells are capable of being activated in an antigen-independent, bystander fashion by a combination of $\mathrm{T}$ cell- and DC-derived soluble mediators. Specifically, sorted, purified IgG+ MZA B cells have the ability to upregulate BLIMP-1, but not AID, following exposure to IL-21 alone. Notably, stimulation with both BAFF and IL-21 results in rapid plasma cell differentiation and production of IgG antibodies. Moreover, the combination of IL-2 and IL-10 which induces plasma cell differentiation of memory splenic B cells co-stimulated with CD40L (Tangye et al., 1998), was significantly less potent at inducing plasma cell differentiation and IgG production from CD21 ${ }^{\text {hi }}$ MZA than the combination of IL-21 and BAFF. The capacity to differentiate into plasma cells in response to IL-21

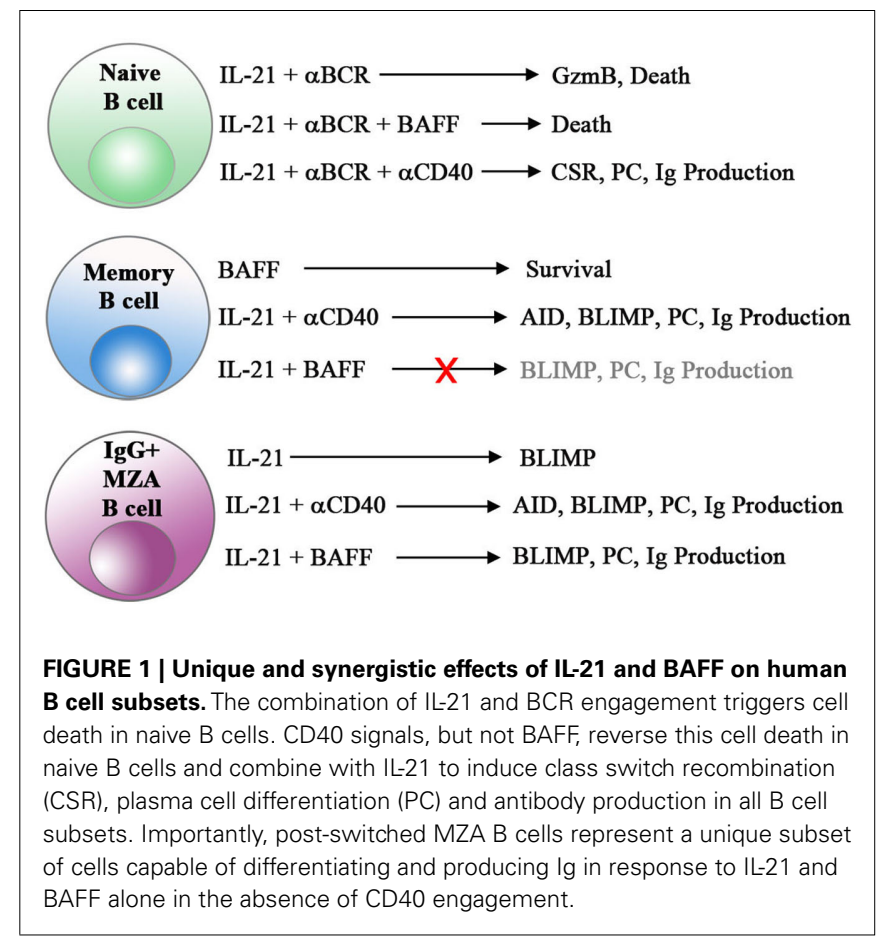

and BAFF in the absence of CD40 or BCR ligation was unique to post-switched MZA, as splenic naïve, memory, or IgG - or IgM+ MZA B cells were unable to respond in this fashion. The ability of BAFF to serve as a surrogate to CD40 signaling may be explained by the fact that BAFF and anti-CD40 both share common signal events via NFKB (Qian et al., 2004; Lin-Lee et al., 2006).

Marginal zone-analog B cells, therefore, represent a population of memory B cells that have the unique capability of responding in an antigen-independent manner to cytokines alone. Importantly, based on their localization in the human spleen in proximity to both T cells capable of producing IL-21 and dendritic cells capable of secreting BAFF (Ettinger et al., 2007), these specialized B cells may very well contribute to the maintenance of serologic memory through rapid plasma cell differentiation and production of high affinity IgG antibodies. Previous studies have reported that compared to post-switched GC B cells, pre-switched MZ B cells from the blood or spleen of infants have high clonal diversity (Weill et al., 2009). A better understanding of the repertoire of post-switched MZA B cells and their autoreactive potential is an area of interest for future studies.

\section{CONCLUSION}

Clearly, IL-21 and BAFF play fundamental roles in regulating various aspects of human humoral immuno-responsiveness including B cell survival, activation, expansion, CSR, plasma cell differentiation, and production of antibodies (Figure 1). As such, these two very influential cytokines are attractive targets for the treatment of autoimmune disease. Although BAFF blockade has proven clinical activity for the treatment of SLE, dual targeting of BAFF with other B cell tropic factors, such as IL-21, may provide additional therapeutic options for this severely debilitating disease. 


\section{REFERENCES}

Asao, H., Okuyama, C., Kumaki, S., Ishii, N., Tsuchiya, S., Foster, D., and Sugamura, K. (2001). Cutting edge: the common gamma-chain is an indispensable subunit of the IL-21 receptor complex. J. Immunol. 167, 1-5.

Avery, D. T., Bryant, V. L., Ma, C. S., de Waal Malefyt, R., and Tangye, S. G. (2008a). IL-21-induced isotype switching to $\operatorname{IgG}$ and IgA by human naive B cells is differentially regulated by IL-4. J. Immunol. 181, 1767-1779.

Avery, D. T., Ma, C. S., Bryant, V. L., Santner-Nanan, B., Nanan, R., Wong, M., Fulcher, D. A., Cook, M. C., and Tangye, S. G. (2008b). STAT3 is required for IL-21-induced secretion of IgE from human naive B cells. Blood 112, 1784-1793.

Avery, D. T., Deenick, E. K., Ma, C. S., Suryani, S., Simpson, N., Chew, G. Y., Chan, T. D., Palendira, U., Bustamante, J., Boisson-Dupuis, S., Choo, S., Bleasel, K. E., Peake, J., King, C., French, M. A., Engelhard, D., Al-Hajjar, S., Al-Muhsen, S., Magdorf, K., Roesler, J., Arkwright, P. D., Hissaria, P., Riminton, D. S., Wong, M., Brink, R., Fulcher, D. A., Casanova, J. L., Cook, M. C., and Tangye, S. G. (2010). B cell-intrinsic signaling through IL-21 receptor and STAT3 is required for establishing long-lived antibody responses in humans. J. Exp. Med. 207, 155-171.

Avery, D. T., Kalled, S. L., Ellyard, J. I., Ambrose, C., Bixler, S. A., Thien, M., Brink, R., Mackay, F., Hodgkin, P. D., and Tangye, S. G. (2003). BAFF selectively enhances the survival of plasmablasts generated from human memory B cells. J. Clin. Invest. 112, 286-297.

Badr, G., Borhis, G., Lefevre, E. A., Chaoul, N., Deshayes, F., Dessirier, V., Lapree, G., Tsapis, A., and Richard, Y. (2008). BAFF enhances chemotaxis of primary human B cells: a particular synergy between BAFF and CXCL13 on memory B cells. Blood 111, 2744-2754.

Becker-Merok, A., Nikolaisen, C., and Nossent, H. C. (2006). Blymphocyte activating factor in systemic lupus erythematosus and rheumatoid arthritis in relation to autoantibody levels, disease measures and time. Lupus 15, 570-576.

Belnoue, E., Pihlgren, M., McGaha, T. L., Tougne, C., Rochat, A. F., Bossen, C., Schneider, P., Huard, B., Lambert, P. H., and Siegrist, C. A. (2008). APRIL is critical for plasmablast survival in the bone marrow and poorly expressed by early-life bone marrow stromal cells. Blood 111, 2755-2764. Benson, M. J., Dillon, S. R., Castigli, E., Geha, R. S., Xu, S., Lam, K. P., and Noelle, R. J. (2008). Cutting edge: the dependence of plasma cells and independence of memory B cells on BAFF and APRIL. J. Immunol. 180, 3655-3659.

Bernasconi, N. L., Traggiai, E., and Lanzavecchia, A. (2002). Maintenance of serological memory by polyclonal activation of human memory B cells. Science 298, 2199-2202.

Bryant, V. L., Ma, C. S., Avery, D. T., Li, Y., Good, K. L., Corcoran, L. M., de Waal Malefyt, R., and Tangye, S. G. (2007). Cytokine-mediated regulation of human B cell differentiation into Ig-secreting cells: predominant role of IL-21 produced by CXCR5+ T follicular helper cells. J. Immunol. 179, 8180-8190.

Cambridge, G., Isenberg, D. A., Edwards, J. C., Leandro, M. J., Migone, T. S., Teodorescu, M., and Stohl, W. (2008). B cell depletion therapy in systemic lupus erythematosus: relationships among serum B lymphocyte stimulator levels, autoantibody profile and clinical response. Ann. Rheum. Dis. 67, 1011-1016.

Cambridge, G., Stohl, W., Leandro, M. J., Migone, T. S., Hilbert, D. M., and Edwards, J. C. (2006). Circulating levels of B lymphocyte stimulator in patients with rheumatoid arthritis following rituximab treatment: relationships with $\mathrm{B}$ cell depletion, circulating antibodies, and clinical relapse. Arthritis Rheum. 54, 723-732.

Cheema, G. S., Roschke, V., Hilbert, D. M., and Stohl, W. (2001). Elevated serum B lymphocyte stimulator levels in patients with systemic immune-based rheumatic diseases. Arthritis Rheum. 44, 1313-1319.

Chtanova, T., Tangye, S. G., Newton, R., Frank, N., Hodge, M. R., Rolph, M. S., and Mackay, C. R. (2004). T follicular helper cells express a distinctive transcriptional profile, reflecting their role as non-Th1/Th2 effector cells that provide help for B cells. $J$. Immunol. 173, 68-78.

Coquet, J. M., Kyparissoudis, K., Pellicci, D. G., Besra, G., Berzins, S. P., Smyth, M. J., and Godfrey, D. I. (2007). IL-21 is produced by NKT cells and modulates NKT cell activation and cytokine production. $J$. Immunol. 178, 2827-2834.

Craxton, A., Magaletti, D., Ryan, E. J., and Clark, E. A. (2003). Macrophage- and dendritic celldependent regulation of human Bcell proliferation requires the TNF family ligand BAFF. Blood 101, 4464-4471.

Dall'Era, M., Chakravarty, E., Wallace, D., Genovese, M., Weisman, M., Kavanaugh, A., Kalunian, K., Dhar, P., Vincent, E., Pena-Rossi, C., and Wofsy, D. (2007). Reduced B lymphocyte and immunoglobulin levels after atacicept treatment in patients with systemic lupus erythematosus: results of a multicenter, phase $\mathrm{Ib}$, double-blind, placebo-controlled, dose-escalating trial. Arthritis Rheum. 56, 4142-4150.

Darce, J. R., Arendt, B. K., Chang, S. K., and Jelinek, D. F. (2007a). Divergent effects of BAFF on human memory B cell differentiation into Ig-secreting cells. J. Immunol. 178, 5612-5622.

Darce, J. R., Arendt, B. K., Wu, X. and Jelinek, D. F. (2007b). Regulated expression of BAFF-binding receptors during human B cell differentiation. J. Immunol. 179, 7276-7286.

Davis, I. D., Skak, K., Smyth, M. J., Kristjansen, P. E., Miller, D. M., and Sivakumar, P. V. (2007). Interleukin21 signaling: functions in cancer and autoimmunity. Clin. Cancer Res. 13 , 6926-6932.

de Totero, D., Meazza, R., Zupo, S., Cutrona, G., Matis, S., Colombo, M., Balleari, E., Pierri, I., Fabbi, M., Capaia, M., Azzarone, B., Gobbi, M., Ferrarini, M., and Ferrini, S. (2006). Interleukin-21 receptor (IL-21R) is up-regulated by CD40 triggering and mediates proapoptotic signals in chronic lymphocytic leukemia B cells. Blood 107, 3708-3715.

Diehl, S. A., Schmidlin, H., Nagasawa, M., van Haren, S. D., Kwakkenbos, M. J., Yasuda, E., Beaumont, T., Scheeren, F. A., and Spits, H. (2008). STAT3-mediated upregulation of BLIMP1 Is coordinated with BCL6 down-regulation to control human plasma cell differentiation. J. Immunol. 180, 4805-4815.

Doreau, A., Belot, A., Bastid, J., Riche, B., Trescol-Biemont, M. C., Ranchin, B., Fabien, N., Cochat, P., Pouteil-Noble, C., Trolliet, P., Durieu, I., Tebib, J., Kassai, B., Ansieau, S., Puisieux, A., Eliaou, J. F., and Bonnefoy-Bérard, N. (2009). Interleukin 17 acts in synergy with B cell-activating factor to influence B cell biology and the pathophysiology of systemic lupus erythematosus. Nat. Immunol. 10, 778-785.

Dunn-Walters, D. K., Isaacson, P. G., and Spencer, J. (1995). Analysis of mutations in immunoglobulin heavy chain variable region genes of microdissected marginal zone (MGZ) B cells suggests that the MGZ of human spleen is a reservoir of memory B cells. J. Exp. Med. 182, 559-566.

Ettinger, R., Kuchen, S., and Lipsky, P. E. (2008a). Interleukin 21 as a target of intervention in autoimmune disease. Ann. Rheum. Dis. 67(Suppl. 3), iii83-iii86.

Ettinger, R., Kuchen, S., and Lipsky, P. E. (2008b). The role of IL-21 in regulating B-cell function in health and disease. Immunol. Rev. 223, 60-86.

Ettinger, R., Sims, G. P., Fairhurst, A. M., Robbins, R., da Silva, Y. S., Spolski, R., Leonard, W. J., and Lipsky, P. E. (2005). IL-21 induces differentiation of human naive and memory $B$ cells into antibody-secreting plasma cells. J. Immunol. 175, 7867-7879.

Ettinger, R., Sims, G. P., Robbins, R., Withers, D., Fischer, R. T., Grammer, A. C., Kuchen, S., and Lipsky, P. E. (2007). IL-21 and BAFF/BLyS synergize in stimulating plasma cell differentiation from a unique population of human splenic memory $\mathrm{B}$ cells. J. Immunol. 178, 2872-2882.

Good, K. L., Bryant, V. L., and Tangye, S. G. (2006). Kinetics of human B cell behavior and amplification of proliferative responses following stimulation with IL-21. J. Immunol. 177, 5236-5247.

Groom, J., Kalled, S. L., Cutler, A. H., Olson, C., Woodcock, S. A., Schneider, P., Tschopp, J., Cachero, T. G., Batten, M., Wheway, J., Mauri, D. Cavill, D., Gordon, T. P., Mackay, C. R., and Mackay, F. (2002). Association of BAFF/BLyS overexpression and altered B cell differentiation with Sjogren's syndrome. J. Clin. Invest. 109, 59-68.

Gross, J. A., Johnston, J., Mudri, S., Enselman, R., Dillon, S. R., Madden, K., Xu, W., Parrish-Novak, J., Foster, D., Lofton-Day, C., Moore, M., Littau, A., Grossman, A., Haugen, H. Foley, K., Blumberg, H., Harrison, K., Kindsvogel, W., and Clegg, C. H. (2000). TACI and BCMA are receptors for a TNF homologue implicated in B-cell autoimmune disease. Nature 404, 995-999.

Habib, T., Senadheera, S., Weinberg, K., and Kaushansky, K. (2002). The common gamma chain (gamma c) is a required signaling component of the IL-21 receptor and supports IL-21-induced cell proliferation via JAK3. Biochemistry 41, 8725-8731.

Hagn, M., Ebel, V., Sontheimer, K., Schwesinger, E., Lunov, O., Beyer, T., Fabricius, D., Barth, T. F., Viardot, A., Stilgenbauer, S., Hepp, J., Scharffetter-Kochanek, K., Simmet, T., and Jahrsdörfer, B. (2010). CD5+ $B$ cells from individuals with systemic lupus erythematosus express 
granzyme B. Eur. J. Immunol. 40, 2060-2069.

Hagn, M., Schwesinger, E., Ebel, V., Sontheimer, K., Maier, J., Beyer, T., Syrovets, T., Laumonnier, Y., Fabricius, D., Simmet, T., and Jahrsdorfer, B. (2009). Human B cells secrete granzyme B when recognizing viral antigens in the context of the acute phase cytokine IL-21. J. Immunol. 183, 1838-1845.

Hagn, M., Sontheimer, K., Dahlke, K., Brueggemann, S., Kaltenmeier, C., Beyer, T., Hofmann, S., Lunov, O., Barth, T. F., Fabricius, D., Tron, K., Nienhaus, G. U., Simmet, T., Schrezenmeier, H., and Jahrsdörfer, B. (2011). Human B cells differentiate into granzyme B-secreting cytotoxic B lymphocytes upon incomplete T-cell help. Immunol. Cell Biol. $1-11$.

Jacobi, A. M., Huang, W., Wang, T., Freimuth, W., Sanz, I., Furie, R., Mackay, M., Aranow, C., Diamond, B., and Davidson, A. (2010). Effect of long-term belimumab treatment on B cells in systemic lupus erythematosus: extension of a phase II, double-blind, placebo-controlled, dose-ranging study. Arthritis Rheum. 62, 201-210.

Jahrsdorfer, B., Blackwell, S. E., Wooldridge, J. E., Huang, J., Andreski, M. W., Jacobus, L. S., Taylor, C. M., and Weiner, G. J. (2006). B-chronic lymphocytic leukemia cells and other B cells can produce granzyme B and gain cytotoxic potential after interleukin21-based activation. Blood 108, 2712-2719.

Jelinek, D. F., and Lipsky, P. E. (1985). The roles of $\mathrm{T}$ cell factors in activation, cell cycle progression, and differentiation of human B cells. J. Immunol. 134, 1690-1701.

Krumbholz, M., Theil, D., Derfuss, T., Rosenwald, A., Schrader, F., Monoranu, C. M., Kalled, S. L., Hess, D. M., Serafini, B., Aloisi, F., Wekerle, H., Hohlfeld, R., and Meinl, E. (2005). BAFF is produced by astrocytes and up-regulated in multiple sclerosis lesions and primary central nervous system lymphoma. J. Exp. Med. 201, 195-200.

Kuchen, S., Robbins, R., Sims, G. P., Sheng, C., Phillips, T. M., Lipsky, P. E., and Ettinger, R. (2007). Essential role of IL-21 in B cell activation, expansion, and plasma cell generation during CD4+ T cell-B cell collaboration. J. Immunol. 179, 5886-5896.

Lanzavecchia, A., and Sallusto, F. (2009). Human B cell memory. Curr. Opin. Immunol. 21, 298-304.
Lavie, F., Miceli-Richard, C., Ittah, M., Sellam, J., Gottenberg, J. E., and Mariette, X. (2007). Increase of B cell-activating factor of the TNF family (BAFF) after rituximab treatment: insights into a new regulating system of BAFF production. Ann. Rheum. Dis. 66, 700-703.

Lin-Lee, Y. C., Pham, L. V., Tamayo, A. T., Fu, L., Zhou, H. J., Yoshimura, L. C., Decker, G. L., and Ford, R. J. (2006). Nuclear localization in the biology of the CD40 receptor in normal and neoplastic human B lymphocytes. J. Biol. Chem. 281, 18878-18887.

Litinskiy, M. B., Nardelli, B., Hilbert, D. M., He, B., Schaffer, A., Casali, P., and Cerutti, A. (2002). DCs induce CD40-independent immunoglobulin class switching through BLyS and APRIL. Nat. Immunol. 3, 822-829.

Massonnet, B., Delwail, A., Ayrault, J. M., Chagneau-Derrode, C., Lecron, J. C., and Silvain, C. (2009). Increased immunoglobulin $\mathrm{A}$ in alcoholic liver cirrhosis: exploring the response of $\mathrm{B}$ cells to Tolllike receptor 9 activation. Clin. Exp. Immunol. 158, 115-124.

Moore, P. A., Belvedere, O., Orr, A., Pieri, K., LaFleur, D. W., Feng, P., Soppet, D., Charters, M., Gentz, R., Parmelee, D., Li, Y., Galperina, O., Giri, J., Roschke, V., Nardelli, B., Carrell, J., Sosnovtseva, S., Greenfield, W., Ruben, S. M., Olsen, H. S., Fikes, J., and Hilbert, D. M. (1999). BLyS: member of the tumor necrosis factor family and B lymphocyte stimulator. Science 285, 260-263.

Navarra, S. V., Guzman, R. M., Gallacher, A. E., Hall, S., Levy, R. A., Jimenez, R. E., Li, E. K., Thomas, M., Kim, H. Y., Leon, M. G., Tanasescu, C., Nasonov, E., Lan, J. L., Pineda, L., Zhong, Z. J., Freimuth, W., Petri, M. A., and BLISS-52 Study Group. (2011). Efficacy and safety of belimumab in patients with active systemic lupus erythematosus: a randomised, placebo-controlled, phase 3 trial. Lancet 377, 721-731.

Ng, L. G., Sutherland, A. P., Newton, R., Qian, F., Cachero, T. G., Scott, M. L., Thompson, J. S., Wheway, J., Chtanova, T., Groom, J., Sutton, I. J., Xin, C., Tangye, S. G., Kalled, S. L., Mackay, F., and Mackay, C. R. (2004). $\mathrm{B}$ cell-activating factor belonging to the TNF family (BAFF)- $R$ is the principal BAFF receptor facilitating BAFF costimulation of circulating $\mathrm{T}$ and $\mathrm{B}$ cells. J. Immunol. 173, 807-817.

NovoNordisk. (2010). First-in-Man Trial of NNC114-0005 in Healthy Subjects and Subjects with Rheumatoid Arthritis. Available at: http://
clinicaltrials.gov/ct2/show/NCT012 08506?term $=$ IL-21\&rank $=11$ Ident ifier: NCT01208506

Ozaki, K., Kikly, K., Michalovich, D. Young, P. R., and Leonard, W. J. (2000). Cloning of a type I cytokine receptor most related to the IL-2 receptor beta chain. Proc. Natl. Acad. Sci. U.S.A. 97, 11439-11444.

Parrish-Novak, J., Dillon, S. R., Nelson, A., Hammond, A., Sprecher, C., Gross, J. A., Johnston, J., Madden, K., Xu, W., West, J., Schrader, S. Burkhead, S., Heipel, M., Brandt, C., Kuijper, J. L., Kramer, J., Conklin, D., Presnell, S. R., Berry, J., Shiota, F., Bort, S., Hambly, K., Mudri, S., Clegg, C., Moore, M., Grant, F. J., Lofton-Day, C., Gilbert, T., Rayond, F., Ching, A., Yao, L., Smith, D. Webster, P., Whitmore, T., Maurer, M., Kaushansky, K., Holly, R. D. and Foster, D. (2000). Interleukin 21 and its receptor are involved in NK cell expansion and regulation of lymphocyte function. Nature 408, 57-63.

Pene, J., Gauchat, J. F., Lecart, S., Drouet, E., Guglielmi, P., Boulay, V., Delwail, A., Foster, D., Lecron, J. C., and Yssel, H. (2004). Cutting edge: IL-21 is a switch factor for the production of IgG1 and IgG3 by human B cells. J. Immunol. 172, 5154-5157.

Pene, J., Guglielmi, L., Gauchat, J. F., Harrer, N., Woisetschlager, M., Boulay, V., Fabre, J. M., Demoly, P., and Yssel, H. (2006). IFN-gammamediated inhibition of human IgE synthesis by IL-21 is associated with a polymorphism in the IL-21R gene. J. Immunol. 177, 5006-5013.

Pfizer. (2010). Study to Assess the Safety and Tolerability of Increasing Single Doses of ATR-107 (PF-05230900) in Healthy People. Available at: http://clinicaltrials.gov/ct2/show/NC T01162889? term=ATR-107\&rank=1 Identifier: NCT01162889

Qian, Y., Qin, J., Cui, G., Naramura, M. Snow, E. C., Ware, C. F., Fairchild, R. L., Omori, S. A., Rickert, R. C., Scott, M., Kotzin, B. L., and Li, X. (2004). Actl, a negative regulator in CD40and BAFF-mediated B cell survival. Immunity 21, 575-587.

Rahman, Z. S., Rao, S. P., Kalled, S. L., and Manser, T. (2003). Normal induction but attenuated progression of germinal center responses in BAFF and BAFF-R signalingdeficient mice. J. Exp. Med. 198, 1157-1169.

Rasheed, A. U., Rahn, H. P., Sallusto, F., Lipp, M., and Muller, G. (2006). Follicular B helper $\mathrm{T}$ cell activity is confined to CXCR5(hi)ICOS(hi) CD4 $\mathrm{T}$ cells and is independent of
CD57 expression. Eur. J. Immunol. 36, 1892-1903.

Scapini, P., Nardelli, B., Nadali, G., Calzetti, F., Pizzolo, G., Montecucco, C., and Cassatella, M. A. (2003). G-CSF-stimulated neutrophils are a prominent source of functional BLyS. J. Exp. Med. 197, 297-302.

Schneider, P., MacKay, F., Steiner, V., Hofmann, K., Bodmer, J. L., Holler, N., Ambrose, C., Lawton, P., Bixler, S., Acha-Orbea, H., Valmori, D., Romero, P., Werner-Favre, C., Zubler, R. H., Browning, J. L., and Tschopp, J. (1999). BAFF, a novel ligand of the tumor necrosis factor family, stimulates B cell growth. J. Exp. Med. 189, 1747-1756.

Scholz, J. L., Crowley, J. E., Tomayko, M. M., Steinel, N., O’Neill, P. J., Quinn, W. J. III, Goenka, R., Miller, J. P., Cho, Y. H., Long, V., Ward, C., Migone, T. S., Shlomchik, M. J., and Cancro, M. P. (2008). BLyS inhibition eliminates primary B cells but leaves natural and acquired humoral immunity intact. Proc. Natl. Acad. Sci. U.S.A. 105, 15517-15522.

Sims, G. P., Ettinger, R., Shirota, Y., Yarboro, C. H., Illei, G. G., and Lipsky, P. E. (2005). Identification and characterization of circulating human transitional B cells. Blood 105, 4390-4398.

Spolski, R., and Leonard, W. J. (2008a). Interleukin-21: basic biology and implications for cancer and autoimmunity. Annu. Rev. Immunol. 26, 57-79.

Spolski, R., and Leonard, W. J. (2008b). The Yin and Yang of interleukin-21 in allergy, autoimmunity and cancer. Curr. Opin. Immunol. 20, 295-301.

Spolski, R., and Leonard, W. J. (2010). IL-21 and T follicular helper cells. Int. Immunol. 22, 7-12.

Tak, P. P., Thurlings, R. M., Rossier, C., Nestorov, I., Dimic, A., Mircetic, V., Rischmueller, M., Nasonov, E., Shmidt, E., Emery, P., and Munafo, A. (2008). Atacicept in patients with rheumatoid arthritis: results of a multicenter, phase Ib, double-blind, placebo-controlled, dose-escalating, single- and repeated-dose study. Arthritis Rheum. 58, 61-72.

Tangye, S. G., Liu, Y. J., Aversa, G., Phillips, J. H., and de Vries, J. E. (1998). Identification of functional human splenic memory B cells by expression of CD148 and CD27. J. Exp. Med. 188, 1691-1703.

Thompson, J. S., Bixler, S. A., Qian, F., Vora, K., Scott, M. L., Cachero, T. G., Hession, C., Schneider, P., Sizing, I. D., Mullen, C., Strauch, K., Zafari, M., Benjamin, C. D., Tschopp, J., Browning, J. L., and Ambrose, 
C. (2001). BAFF-R, a newly identified TNF receptor that specifically interacts with BAFF. Science 293, 2108-2111.

Thompson, J. S., Schneider, P., Kalled, S. L., Wang, L., Lefevre, E. A., Cachero, T. G., MacKay, F., Bixler, S. A., Zafari, M., Liu, Z. Y., Woodcock, S. A., Qian, F., Batten, M., Madry, C., Richard, Y., Benjamin, C. D., Browning, J. L., Tsapis, A., Tschopp, J., and Ambrose, C. (2000). BAFF binds to the tumor necrosis factor receptor-like molecule $\mathrm{B}$ cell maturation antigen and is important for maintaining the peripheral B cell population. J. Exp. Med. 192, 129-135.

Wallace, D. J., Stohl, W., Furie, R. A., Lisse, J. R., McKay, J. D., Merrill, J. T., Petri, M. A., Ginzler, E. M., Chatham, W. W., McCune, W. J., Fernandez, V., Chevrier, M. R., Zhong, Z. J., and Freimuth, W. W. (2009). A phase II, randomized, double-blind, placebo-controlled, dose-ranging study of belimumab in patients with active systemic lupus erythematosus. Arthritis Rheum. 61, 1168-1178.

Webb, R., Merrill, J. T., Kelly, J. A., Sestak, A., Kaufman, K. M., Langefeld, C. D., Ziegler, J., Kimberly, R. P., Edberg, J. C., Ramsey-Goldman, R., Petri, M., Reveille, J. D., Alarcón, G. S., Vilá, L. M., Alarcón-Riquelme, M. E., James, J. A., Gilkeson, G. S., Jacob, C. O., Moser, K. L., Gaffney, P. M., Vyse, T. J., Nath, S. K., Lipsky, P., Harley, J. B., and Sawalha, A. H. (2009). A polymorphism within IL21R confers risk for systemic lupus erythematosus. Arthritis Rheum. 60, 2402-2407.

Weill, J. C., Weller, S., and Reynaud, C. A. (2009). Human marginal zone B cells. Annu. Rev. Immunol. 27, 267-285.

Weller, S., Reynaud, C. A., and Weill, J. C. (2005). Splenic marginal zone B cells in humans: where do they mutate their Ig receptor? Eur. J. Immunol.35, 2789-2792.

Wong, C. K., Wong, P. T., Tam, L. S. Li, E. K., Chen, D. P., and Lam, C. W. (2010). Elevated production of B cell chemokine CXCL13 is correlated with systemic lupus erythematosus disease activity. J. Clin. Immunol. 30 , 45-52.

Wood, N., Bourque, K., Donaldson, D. D., Collins, M., Vercelli, D., Goldman, S. J., and Kasaian, M. T. (2004). IL-21 effects on human IgE production in response to IL4 or IL-13. Cell. Immunol. 231, 133-145.

Zhang, X., Park, C. S., Yoon, S. O., Li, L., Hsu, Y. M., Ambrose, C., and Choi, Y. S. (2005). BAFF supports human B cell differentiation in the lymphoid follicles through distinct receptors. Int. Immunol. 17, 779-788.

Conflict of Interest Statement: The authors declare that the research was conducted in the absence of any commercial or financial relationships that could be construed as a potential conflict of interest.

Received:06 October 2011; paperpending published: 16 November 2011; accepted: 05 January 2012; published online: 24 January 2012.

Citation: Karnell $J L$ and Ettinger $R$ (2012) The interplay of IL-21 and BAFF in the formation and maintenance of human B cell memory. Front. Immun. 3:2. doi: 10.3389/fimmu.2012.00002

This article was submitted to Frontiers in B Cell Biology, a specialty of Frontiers in Immunology.

Copyright (c) 2012 Karnell and Ettinger. This is an open-access article distributed under the terms of the Creative Commons Attribution Non Commercial License, which permits non-commercial use, distribution, and reproduction in other forums, provided the original authors and source are credited. 